\title{
Physiotherapy in Treatment of Oral Submucous Fibrosis Related Restricted Mouth Opening
}

\section{ASHA V ${ }^{1}$, NEVICA BARUAH ${ }^{2}$}

BACKGROUND: Multiple treatment approaches including surgical and non surgical therapies have been tried to improve restricted mouth opening in Oral Submucous Fibrosis (OSMF).

AIM: To evaluate the effectiveness of physiotherapy in improving mouth opening, tongue protrusion and cheek flexibility in patients with OSMF.

MATERIALS AND METHODS: Forty eight OSMF patients were assigned into three groups by drawing chits. Group 1: patients receiving intralesional injections of dexamethasone and hyaluronidase; Group 2: patients receiving physiotherapy; Group 3: patients receiving both intralesional injections and physiotherapy. Mouth opening, tongue protrusion and cheek flexibility was assessed in all the patients before intervention and at different time intervals of 2 weeks, 4 weeks and 6 weeks after treatment.

RESULTS: Intragroup: In Group 2, the mean values of mouth opening, tongue protrusion and cheek flexibility were increased in time but were statistically insignificant. The mean values of mouth opening, tongue protrusion and cheek flexibility were markedly increased over a period of time in Group 3 and cheek flexibility was found to be statistically significant $(p=0.05)$.

Intergroup: The mean differences of mouth opening, cheek flexibility and tongue protrusion was found to be maximum in group 3 and it was statistically significant $(\mathrm{p}=\mathrm{0.03}$ ) for tongue protrusion.

CONCLUSION: Concurrent treatment with physiotherapy and intralesional injections was found to improve the mean mouth opening, tongue protrusion and cheek flexibility. Hence, physiotherapy can be used as an adjuvant treatment for OSMF as it is non invasive, more patient compliant and doesn't require any financial resources.

KEYWORDS: Oral Submucous Fibrosis, Physical Therapy Modalities, Trismus, Exercise

\section{INTRODUCTION}

Oral Submucous Fibrosis (OSMF) is a chronic disease affecting the oral mucosa, as well as the pharynx and the upper two thirds of the esophagus. It is characterized by burning sensation in the oral cavity, blanching and stiffening of the oral mucosa and oropharynx which ultimately leads to trismus.1

Various etiologies have been proposed earlier including chillies, nutritional deficiency, autoimmunity and genetic susceptibility.2 Presently, the etiology of OSMF is mainly attributed to the use of areca nut and quid chewing habit.3 Areca nuts contain alkaloids, of which arecoline seems to be a primary etiologic factor. Arecoline has the capacity to modulate matrix metalloproteinases, lysyl oxidases, and collagenases which affects the metabolism of collagen leading to an increased fibrosis. 4

Steroids have been the mainstay of treatment for OSMF. Steroids inhibit the proliferation of fibroblasts and this causes reduction in the number of collagen fibres. They act to release cellular proteases in the connective tissue extracellular component which in turn activates the collagens and zymogen that ingest the insoluble collagen stimulating the rate of collagen breakdown. But disadvantages of intralesional steroids like patient discomfort and fibrosis due to needle trauma has led to research on other interventions.5 One such intervention is physiotherapy which encompasses mouth exercises, heat, therapeutic ultrasound and microwave diathermy. Physiotherapy is a non invasive modality which may aid in the symptomatic treatment of patients with OSMF.

The treatment for patients who are unwilling for intralesional injections can be advised to do mouth exercises to increase the mouth opening, tongue protrusion and cheek flexibility.

The aim of this study was to assess the efficacy of physiotherapy in improving mouth opening, 
tongue protrusion and cheek flexibility in patients with OSMF.

\section{MATERIALS AND METHODS}

Prior to study, ethical clearance was obtained from the institutional review board. The study population consisted of 48 OSMF patients aged between 16-50 years showing clinical evidence of OSMF stage II (according to Pindborg's classification) and with subjective reduction in mouth opening less than $35 \mathrm{~mm}$ and reduced cheek flexibility. Patients with mouth opening of less than $12 \mathrm{~mm}$, patients with reduced mouth opening due to temporomandibular disorders or third molar impaction and patients diagnosed with oral squamous cell carcinoma were excluded from the study.

Simple Random sampling technique was used to distribute the sample size into three groups numbered 1, 2, 3 by picking up paper chits. All the patients were also counselled to quit areca nut chewing habit and given lycopene $4 \mathrm{mg}$ once a day for a month. A complete haemogram was done for all patients and were advised to take a haematinic syrup or referred to a physician if found to be anemic.

Group 1 patients were treated with Intralesional injections of hyaluronidase $\left(\begin{array}{lll}1500 & U\end{array}\right)$ and dexamethasone $(4 \mathrm{mg} / \mathrm{ml})$ biweekly for 6 weeks, Group 2 patients were treated with basic Physiotherapy regimen consisting of mouth exercises (Figure 1) twice a day for 6 weeks and Group 3 patients were treated with both Physiotherapy and Intralesional injections.

Mouth opening, tongue protrusion and cheek flexibility were measured before intervention and at intervals of 2 weeks, 4 weeks and 6 weeks after treatment. The maximum inter-incisal distance using geometric divider and scale was measured as the mouth opening. Tongue protrusion was measured as the distance between incisal edge of maxillary incisors and position of maximum tongue protrusion. For cheek flexibility, two points were marked on both the cheeks of the patients at $1 / 3$ rd the distance from the angle of the mouth on a line joining the tragus and the angle of the mouth. The patients were then asked to blow their cheeks fully and distance was measured between these two points. This depicted the cheek fullness with air. The subjects were then asked to blow out the air and relax and distance was measured again between the two points. The difference between these two values depicted the cheek flexibility. ${ }^{6}$

\section{Statistical Analysis}

Intragroup and intergroup analysis was done using Analysis of variance (ANOVA) to assess the mean values of mouth opening, tongue protrusion and cheek flexibility. The $\mathrm{p}-$ value of $<0.05$ was considered as statistically significant.

\section{RESULTS}

A dropout of 3 patients per group was seen with the final sample size of 39 patients which was analysed statistically. The parameters of mouth opening, tongue protrusion and cheek flexibility were assessed within each group at a time interval of 2 weeks, 4 weeks and 6 weeks. Also, an intergroup analysis was done for the same three parameters before initiation of treatment to the end of 6 weeks.

Intergroup analysis revealed that mean difference in mouth opening before initiation of treatment to end of 6 weeks was maximum in Group 3 [Physiotherapy and injection] (4.80 \pm 3.4$)$ followed by Group 1 [Injection] (4.0 \pm 2.8$)$ and Group 2 [Physiotherapy] (2.73 \pm 1.7$)$. The mean difference was also highest for tongue protrusion and cheek flexibility in Group 3 with value of $8.30 \pm 4.5$ and $0.25 \pm 0.2$ respectively. The mean difference of cheek flexibility in Group 1 was comparable to the Group 3 with value of $0.2 \pm 0.2$ while it was lesser when compared to the same for tongue protrusion (6.31 \pm 2.7$)$. Group 2 showed least values for tongue protrusion $(4.92 \pm 1.7)$ and cheek flexibility (o.1 \pm 0.1$)$. The mean difference of tongue protrusion among the three groups was found to be statistically significant ( $\mathrm{p}=0.033)$ (Table 1 ).

Cheek flexibility was found to be statistically significant in Group 3 ( $\mathrm{p}=0.05)$ when analyzed at specific intervals of 2 weeks, 4 weeks and 6 weeks while tongue protrusion was statistically significant in Group 1 ( $\mathrm{p}=0.048)$ (Table 2).

\section{DISCUSSION}

Submucous fibrosis of the oral cavity was first described by Schwartz in 1952 in five Indian females from Kenya and East Africa. Initially the 
term "atrophia idiopathica mucosae oris" was proposed, which was later replaced by the term currently being used. 7 The prevalence in India ranges from 0.2 to 0.5 percent with a higher predominance in the southern parts of the subcontinent. Individuals between the ages of 20 $\& 40$ years are most commonly affected but cases have been reported in patients ranging from two years to eighty nine years of age. ${ }^{8}$

Multiple treatment approaches for OSMF including both medical and surgical interventions has been tried. Since chewing of areca nut have been considered as one of the significant etiologies in the pathogenesis of OSMF, the primary therapy should be cessation of habit. Hence, patients should be counselled to quit the habit. The patients in this study were advised for oral prophylaxis which motivated the patients to not indulge in the habit again and also helped us to monitor any patients who had continued the habit.

Medical therapies like corticosteroids, ${ }^{9}$ placental extracts, ${ }^{10}$ hyaluronidase, ${ }^{11}$ pentoxifylline ${ }^{8}$ etc. have been used earlier which has been found to have good results. Surgery is indicated in patients with severe trismus when other techniques have failed to improve the condition. But the results are not satisfactory as there is contracture of wound healing leading to more fibrosis. ${ }^{12}$ Intralesional corticosteroids like dexamethasone is the most widely used treatment in India and numerous studies have proved its efficacy in improving mouth opening in OSMF patients. But it has low patient compliance, with many patients failing to return for their subsequent follow ups due to needle trauma and trypanophobia. Thus physiotherapy can be used as an alternate therapy to improve mouth opening in such patients with OSMF.

Researches using different physiotherapeutic modalities have shown to improve restricted mouth opening in OSMF patients. ${ }^{13,14}$ Physiotherapy has been used in the form of forceful mouth opening to jaw opening devices.

Forceful mouth opening has been almost discarded owing to the poor results and the fact that it may accentuate the fibrosis. Heat has also been commonly used and the results have been described as satisfactory. ${ }^{12}$

Usually, physiotherapy is incorporated postsurgery to aid in increase in mouth opening with the help of jaw opening devices and tongue spatulas. It is seldom used as a sole or primary treatment modality in improving the symptoms in OSMF patients. Physiotherapy has the benefits of being a non-invasive technique, being less traumatic to the patient and requiring no financial sources. Mouth exercises can be performed anywhere during the day which adds to its benefit as a patient compliant technique.

The present study incorporated a mouth exercise regimen ${ }^{15}$ used in patients suffering from dysphagia. To the best of our knowledge this regimen has been used for the first time in OSMF patients. The efficacy of these mouth exercises in treating patients with OSMF was assessed and a mean increase in mouth opening, tongue protrusion and cheek flexibility was found in patients performing mouth exercises. A marked increase in all the three parameters was noted in the group treated with both intralesional injections and physiotherapy. The improvement in the physiotherapy group was to a lesser degree than the other two groups for all three parameters. This may be attributed to negligence on the patients' part to perform the exercises regularly as advised. Also, since follow up visits were spaced at a time interval of 2 weeks, the patients were motivated less to perform the exercises regularly. On the other hand, patients receiving biweekly injections and performing physiotherapy exercises were regularly reinforced to perform the exercises due to which the benefits of both physiotherapy and intralesional injections were shown in the results.

\section{CONCLUSION}

In this study, physiotherapy used alone was shown to improve the mean mouth opening, tongue protrusion and cheek flexibility but was not statistically significant. But the simultaneous use of physiotherapy and intralesional injections was found to improve these parameters better than physiotherapy alone. This suggests that use of these modalities together with patient motivation can aid in better management of the signs and symptoms of patients with OSMF. Physiotherapy can be used as an adjuvant 
treatment modality which can potentiate the action of other treatments like intralesional steroids. As physiotherapy requires less resources and is non traumatic, it is more preferred by patients. Therefore, physiotherapy should be included as an adjunct therapy for treating patients with OSMF. It can be also implemented as a primary treatment in patients unwilling for intralesional steroids.

\section{REFERENCES}

1. Ali FM, Patil A, Patil K, Prasant MC. Oral submucous fibrosis and its dermatological relation. Indian Dermatol Online J;5(3):26o-5.

2. Yadav S, Verma A, Sachdeva A, Virdi M. Etiopathogenesis and Management of oral submucous fibrosis. The Internet Journal of Bioengineering 2010;5(1):1-7.

3. Prabhu RV, Prabhu V, Chatra L, Shenai P, Suvarna N, Dandekeri S. Areca nut and its role in oral submucous fibrosis. J Clin Exp Dent 2014;6(5):e569-75.

4. Glick M. Burket's Oral medicine. Twelfth. Shelton, Connecticut: People's Medical Publishing House-USA; 2015.

5. Balabaskaran K, Srinivasan LA. Treatment options for oral submucous fibrosis. IOSR Journal of Dental and Medical Sciences 2013;10(5):33-5.

6. Mathur RM, Jha T. Normal oral flexibility- a guideline for SMF cases. JIDA 1993;64(4):139-43.

7. Rajendran R. Oral submucous fibrosis: etiology, pathogeneis and future research. Bull World Health Organ 1994; 72(6): 985-96.

8. Aara A, Satishkumar GP, C Vani, Venkat Reddy M, Sreekanth K, Ibrahim M. Comparative Study of Intralesional Dexamethasone, Hyaluronidase \& Oral Pentoxifylline in Patients with Oral Submucous Fibrosis. Global Journal of Medical Research 2012;12(7):1-14.

9. Singh M, Niranjan HS, Mehrotra R, Sharma D, Gupta SC. Efficacy of hydrocortisone acetate/hyaluronidase vs triamcinolone acetonide/hyaluronidase in the treatment of oral submucous fibrosis. Indian J Med Res 2010;131:66569.

10. Katharia SK, Singh SP, Kulshreshtha VK. The Effects Of Placenta Extract In Management Of Oral Submucous Fibrosis. Indian Journal of Pharmacology 1992; 24:181-3.

11. James L, Shetty A, Rishi D, Abraham M. Management of Oral Submucous Fibrosis with Injection of Hyaluronidase and Dexamethasone in
Grade III Oral Submucous Fibrosis: A Retrospective Study. J Int Oral Health. 2015 Aug; $7(8): 82-5$.

12. Madalli V, Basavaraddi S, Burde K, Horatti P. Oral submucous fibrosis - an overview. International Journal of Dental Research \& Development 2014;4(2):1-16.

13. Cox S, Zoellner H. Physiotherapeutic treatment improves oral opening in oral submucous fibrosis. J Oral Pathol Med 2009;38:220-6.

14. Thakur N, Keluskar V, Bagewadi A, Shetti A. Effectiveness of Micronutrients and Physiotherapy in the Management of Oral Submucous Fibrosis. Int Journal of Contemporary Dentistry 2011;2(1):101-5.

15. Oral images [Internet]. Available from: http://www.alimed.com/oral-images.html 
Source of support: Nil, Conflict of interest: None declared

Cite this article as:

Asha V, Baruah N. Physiotherapy in Treatment of Oral Submucous Fibrosis Related Restricted Mouth Opening. Int Healthcare Res J 2017;1(8):252-257

AUTHOR AFFILIATIONS

1. MDS, Department of Oral Medicine and Radiology, The Oxford Dental College, Bengaluru

2. BDS, Department of Oral Medicine and Radiology, The Oxford Dental College, Bengaluru

\section{Corresponding Author:}

Dr. Nevica Baruah

Department of Oral Medicine and Radiology

The Oxford Dental College

$10^{\text {th }}$ milestone, Bommanahalli, Hosur road

Bangalore- 560068, India.

+91 9742394380

nevica.baruah@gmail.com

\section{LEGENDS}

\begin{tabular}{|c|c|c|c|c|}
\hline Group & No of samples & Mouth opening & Tongue protrusion & Cheek flexibility \\
\hline Injection & 13 & $4.0 \pm 2.8$ & $6.31 \pm 2.7$ & $0.2 \pm 0.2$ \\
\hline Physiotherapy & 13 & $2.73 \pm 1.7$ & $4.92 \pm 1.7$ & $0.1 \pm 0.1$ \\
\hline Injection \& Physiotherapy & 13 & $4.80 \pm 3.4$ & $8.30 \pm 4.5$ & $0.25 \pm 0.2$ \\
\hline P value & & 0.163 & 0.033* & 0.304 \\
\hline
\end{tabular}

Table 1. Comparison of mean difference (before intervention- 6weeks) [Mean $\pm \mathrm{SD}$ ] among all the groups. $\left(\mathrm{p}<0.05-\right.$ Significant $^{*}, \mathrm{p}<0.001-$ Highly significant ${ }^{* *}$ ) 


\begin{tabular}{|c|c|c|c|c|c|c|c|c|c|c|c|c|c|c|c|}
\hline Group & & Mo & th openil & & & & Tong & le protru & & & & Che & k flexil & & \\
\hline & Initial & $\begin{array}{c}\text { 2week } \\
\text { s }\end{array}$ & $\begin{array}{c}\text { 4week } \\
\text { s }\end{array}$ & $\begin{array}{c}\text { 6week } \\
\mathrm{s}\end{array}$ & $\begin{array}{c}\mathbf{P} \\
\text { val } \\
\text { ue }\end{array}$ & Initial & $\begin{array}{c}\text { 2week } \\
\text { s }\end{array}$ & $\begin{array}{c}\text { 4week } \\
\text { s }\end{array}$ & $\begin{array}{c}\text { 6week } \\
\text { s }\end{array}$ & $\begin{array}{c}\text { p } \\
\text { valu } \\
\text { e }\end{array}$ & Initial & $\begin{array}{c}\text { 2wee } \\
\text { ks }\end{array}$ & $\begin{array}{c}\text { 4wee } \\
\text { ks }\end{array}$ & $\begin{array}{c}\text { 6wee } \\
\text { ks }\end{array}$ & $P$ value \\
\hline Injection & $\begin{array}{c}27.07 \pm \\
6.1\end{array}$ & $\begin{array}{c}28.84 \pm \\
5.0\end{array}$ & $\begin{array}{c}30.30 \pm \\
4.4\end{array}$ & $\begin{array}{c}31.07 \pm \\
4.9\end{array}$ & $\begin{array}{l}0.2 \\
21\end{array}$ & $\begin{array}{c}35.92 \pm \\
5.5\end{array}$ & $\begin{array}{c}37.61 \pm \\
5.6\end{array}$ & $\begin{array}{c}40.23 \pm \\
5.9\end{array}$ & $\begin{array}{c}42.23 \pm \\
6.8\end{array}$ & $\begin{array}{l}0.04 \\
8 *\end{array}$ & $\begin{array}{c}0.76 \pm 0 . \\
3\end{array}$ & $\begin{array}{c}0.67 \pm \\
0.2\end{array}$ & $\begin{array}{c}0.66 \pm \\
0.1\end{array}$ & $\begin{array}{c}0.6 \pm 0 \\
.2\end{array}$ & 0.259 \\
\hline $\begin{array}{c}\text { Physiothe } \\
\text { rapy }\end{array}$ & $\begin{array}{c}28.92 \pm \\
4.6\end{array}$ & $\begin{array}{c}30.07 \pm \\
5.6\end{array}$ & $\begin{array}{c}30.76 \pm \\
5.8\end{array}$ & $\begin{array}{c}31.65 \pm \\
6.1\end{array}$ & $\begin{array}{l}0.6 \\
45\end{array}$ & $\begin{array}{c}38.92 \pm \\
7.1\end{array}$ & $\begin{array}{c}41.11 \pm \\
7.4\end{array}$ & $\begin{array}{c}42.88 \pm \\
7.5\end{array}$ & $\begin{array}{c}43.84 \pm \\
7.4\end{array}$ & $\begin{array}{c}0.34 \\
9\end{array}$ & $\begin{array}{c}0.75 \pm 0 . \\
2\end{array}$ & $\begin{array}{c}0.79 \pm \\
0.3\end{array}$ & $\begin{array}{c}0.73 \pm \\
0.2\end{array}$ & $\begin{array}{c}0.65 \pm \\
0.2\end{array}$ & 0.482 \\
\hline $\begin{array}{c}\text { Injection } \\
\qquad \& \\
\text { Physiothe } \\
\text { rapy }\end{array}$ & $\begin{array}{c}26.50 \pm \\
4.3\end{array}$ & $\begin{array}{c}29.46 \pm \\
5.9\end{array}$ & $\begin{array}{c}30.88 \pm \\
5.7\end{array}$ & $\begin{array}{c}31.31 \pm \\
5.9\end{array}$ & $\begin{array}{l}0.1 \\
22\end{array}$ & $\begin{array}{c}38.23 \pm \\
6.7\end{array}$ & $\begin{array}{c}41.84 \pm \\
8.1\end{array}$ & $\begin{array}{c}44.23 \pm \\
8.4\end{array}$ & $\begin{array}{c}46.53 \pm \\
8.5\end{array}$ & $\begin{array}{c}0.06 \\
5\end{array}$ & $\begin{array}{c}0.81 \pm 0 . \\
2\end{array}$ & $\begin{array}{c}0.68 \pm \\
0.1\end{array}$ & $\begin{array}{c}0.64 \pm \\
0.1\end{array}$ & $\begin{array}{c}0.56 \pm \\
0.2\end{array}$ & $0.05^{*}$ \\
\hline
\end{tabular}

Table 2. Comparison of mouth opening, tongue protrusion and cheek flexibility (Mean \pm SD) at different time intervals. $\left(\mathrm{p}<0.05\right.$ - Significant ${ }^{*}, \mathrm{p}<0.001$ - Highly significant ${ }^{* *}$ )

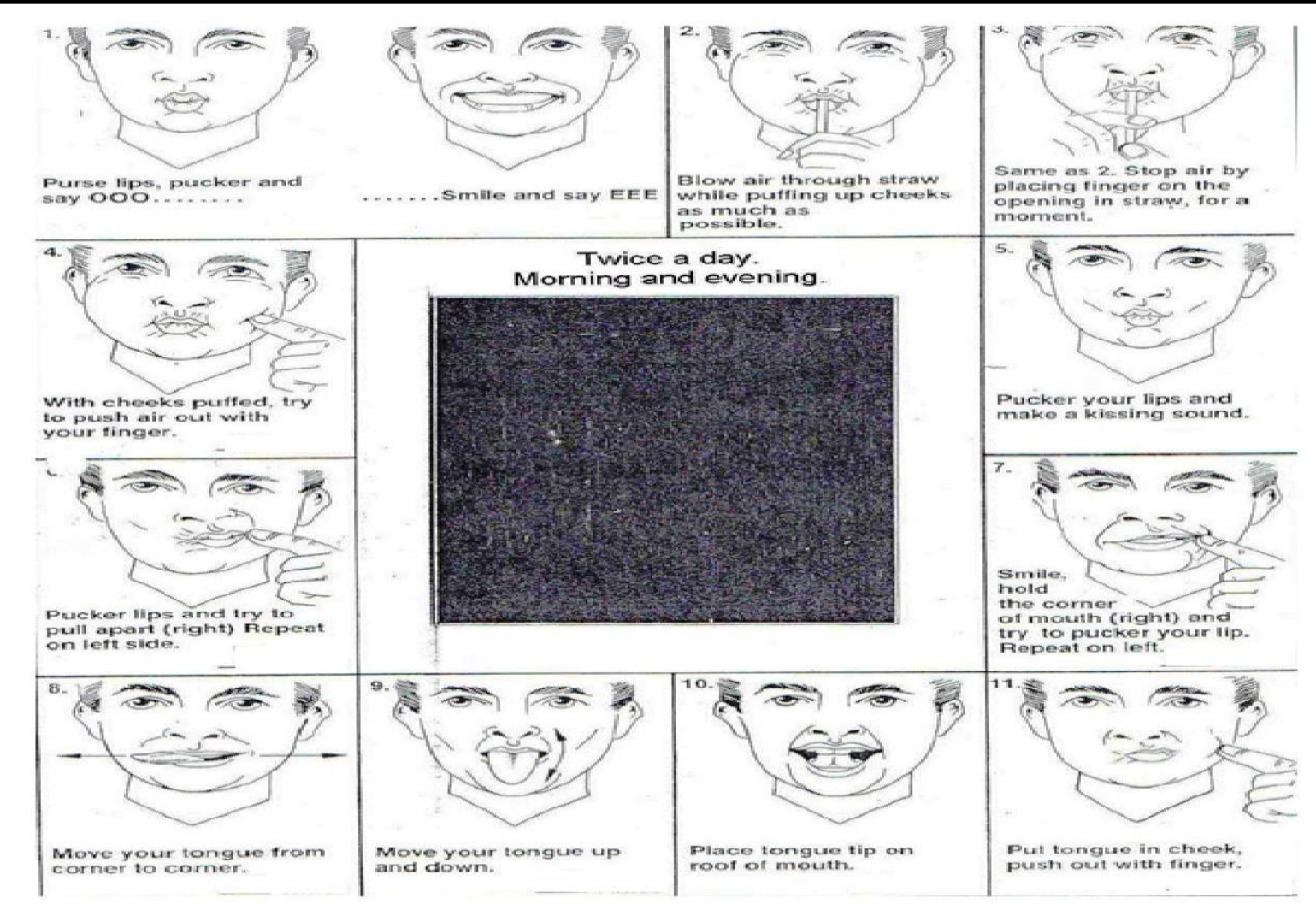

Figure 1. Mouth exercise regimen advised to the patients in Group 2 and 3 